\title{
Leukemic Phase of B-Cell Lymphomas Mimicking Chronic Lymphocytic Leukemia and Variants at Presentation
}

\author{
Beverly P. Nelson, M.D., Daina Variakojis, M.D., LoAnn C. Peterson, M.D. \\ Section of Hematopathology, Northwestern University Medical School, Chicago, Illinois
}

Six cases of non-Hodgkin B-cell lymphoma that mimicked either chronic lymphocytic leukemia (CLL) or a CLL variant at presentation are reported. The patients ranged from 54 to 89 years and included three females and three males. All six patients had prominent peripheral blood lymphocytosis at presentation; the initial morphologic impression was CLL in three cases, CLL/prolymphocytic leukemia (PLL) in two cases, and PLL in one. Five patients had bone marrow biopsies; each showed a lymphoid infiltrate in a focally random, interstitial, and/or diffuse pattern. Flow cytometric immunophenotyping showed CD20-positive B cells with surface immunoglobulin (Ig) light chain restriction in all six patients. The five cases resembling CLL or CLL/PLL had at least a subset of CD5positive $B$ cells, whereas CD5 was absent in the one case that resembled PLL. CD23 was positive in three of the four cases studied that resembled CLL or CLL/PLL; CD79b was positive in three, FMC7 was positive in two, and surface Ig and CD20 were brightly positive in three. $A \mathrm{t}(11 ; 14)(\mathrm{q} 13 ; \mathrm{q} 32)$ was found in four cases that resembled CLL or CLL/PLL; they were subsequently diagnosed as mantle cell lymphoma. The remaining two cases mimicking CLL or PLL were diagnosed as lymphomas of follicle center origin with leukemic phase based on the presence of $t(14 ; 18)(q 32 ; q 21)$. Thus although the morphology of these six cases resembled CLL or variants, and immunophenotyping by flow cytometry showed overlapping features, genetic studies enabled distinction of these leukemic non-Hodgkin lymphoma from chronic lymphocytic leukemia or variants.

Copyright (C) 2002 by The United States and Canadian Academy of Pathology, Inc.

VOL. 15, NO. 11, P. 1111, 2002 Printed in the U.S.A.

Date of acceptance: July 3, 2002.

Address reprint requests to: Beverly P. Nelson, M.D., Northwestern Memorial Hospital, Galter 7-239, 251 E. Huron, Chicago, IL 60611; e-mail: bpnelson@northwestern.edu; fax: 312-926-0560.

DOI: 10.1097/01.MP.0000031710.32235.24
KEY WORDS: Chronic lymphocytic leukemia, FISH, Follicle center lymphoma, Mantle cell lymphoma, Prolymphocytic leukemia.

Mod Pathol 2002;15(11):1111-1120

Chronic lymphocytic leukemia is a disease of older adults. The clinical course is variable; many patients have an indolent, slowly progressive disease lasting several years, whereas others have a more rapid downhill course with survival of less than 1-2 years $(1,2)$. CLL is characterized by absolute lymphocytosis in the peripheral blood and bone marrow at the time of diagnosis. The lymphocytes are typically small and mature appearing, but $\leq 10 \%$ circulating prolymphocytes may be present. CLL/ prolymphocytic leukemia (PLL) is the designation used when between 10 and 55\% prolymphocytes are present at diagnosis. Cases with $>55 \%$ prolymphocytes are regarded as PLL (3). Patients with de novo PLL typically present with high white blood cell counts, splenomegaly, and clinically aggressive disease (3).

Non-Hodgkin lymphomas also may have extensive bone marrow and peripheral blood involvement at initial presentation. Lymphomas that frequently exhibit circulating lymphoma cells include mantle cell lymphoma (MCL) and follicle center lymphoma (FCL; 4-6); however, a prominent peripheral blood lymphocytosis at diagnosis is uncommon. Circulating FCL cells are typically small with scant cytoplasm and cleaved or irregular nuclei. Cells from MCL are usually intermediate in size with variable morphology, including round or irregular nuclei, frequent visible nucleoli, and variable amounts of cytoplasm (7-9).

Recognition of the leukemic counterpart of nonHodgkin lymphoma is facilitated when the leukemia occurs as a late complication of preexisting disease. Non-Hodgkin lymphoma is less obvious if a leukemic phase occurs at presentation. We describe the clinical, morphologic, immunophenotypic, and cytogenetic findings of 6 cases of nonHodgkin, B-cell lymphomas that presented with 
extensive peripheral blood involvement and that were morphologically indistinguishable from CLL, CLL/PLL, or PLL.

\section{METHODS/CASE REPORTS}

Four cases of B-cell lymphoma that manifested with leukocytosis and absolute lymphocytosis and morphology resembling CLL or variants were encountered between December 1998 and September 2001. Two additional cases, one from 1989 and the other from 1993, were identified retrospectively from the files of one author (LP). Each patient had a complete blood cell count with differential. Bone marrow aspirates and biopsies were obtained from all but one patient (Case 3), and a lymph node biopsy was obtained from one patient (Case 2). Sections of bone marrow and lymph node were fixed in formalin or B5, routinely processed, and stained with hematoxylin and eosin (H\&E). WrightGiemsa-stained peripheral blood smears and Wright-Giemsa-stained bone marrow aspirate smears were reviewed. Immunophenotyping by flow cytometry of bone marrow aspirate and/or peripheral blood was performed as previously described (10). Samples were stained and analyzed within 24 hours of collection. Immunohistochemistry for cyclin D1 (clone DCS-6, DAKO Corporation, Carpenteria, CA) was performed on formalinfixed, paraffin-embedded lymph node sections. Conventional cytogenetic studies were performed as previously published (11). Fluorescence in situ hybridization (FISH) was performed according to the manufacturer's directions using commercially available $t(11 ; 14)$ and $t(14 ; 18)$ dual-fusion probes (Vysis, Downers Grove, IL).

\section{Case 1}

A 71-year-old female was diagnosed with CLL in September 1997 based on an absolute lymphocytosis in the peripheral blood with mature-appearing lymphocytes. She was monitored for disease progression but not treated. Three years after the initial diagnosis (August 2000), she was referred to Northwestern Memorial Hospital for further evaluation because of increased fatigue as well as new onset of splenomegaly and cervical lymphadenopathy.

At the time of referral, the white blood cell count (white blood cell count) was $143.4 \times 10^{9} / \mathrm{L}$; hemoglobin (Hgb), $10.8 \mathrm{~g} / \mathrm{dL}$; and platelets (PLT), $146 \times$ $10^{9} / \mathrm{L}$. The differential showed $94 \%$ lymphocytes, $4 \%$ neutrophils, and $2 \%$ monocytes. The lymphocytes were mostly small and mature appearing but included $15 \%$ larger cells with ample cytoplasm and central nucleoli consistent with prolymphocytes (Fig. 1A). A presumptive diagnosis of CLL/PLL was made based on the morphologic findings, and fur-

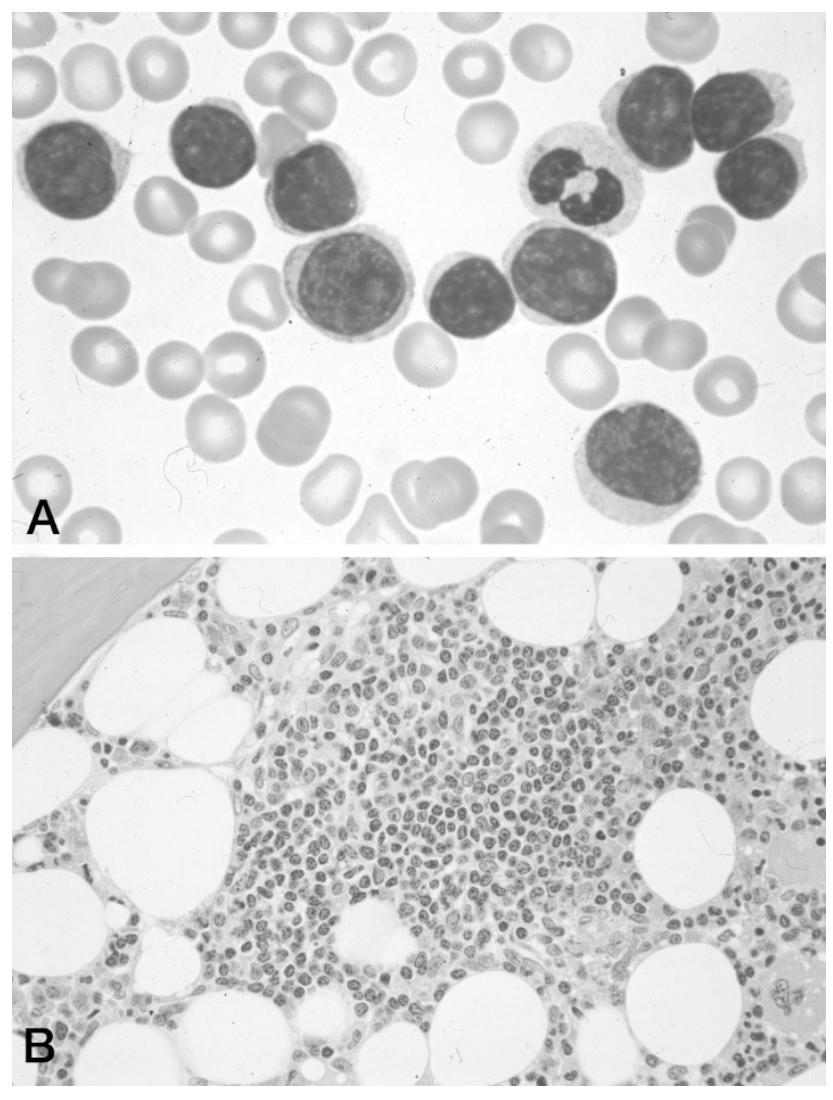

FIGURE 1. Patient 1. A, Peripheral blood smear from a patient with mantle cell lymphoma resembling CLL/PLL. The majority of the lymphocytes are small, mature appearing; a few show looser chromatin and large nucleoli. B, Bone marrow core biopsy involved by mantle cell lymphoma showing one of multiple intertrabecular lymphoid aggregates.

ther studies were recommended. A bone marrow biopsy showed random focal nodular and an interstitial lymphoid infiltrate composed of small lymphocytes with condensed chromatin and about $20 \%$ large lymphoid cells with distinct nucleoli (Fig. 1B)

Immunophenotyping by flow cytometry of the peripheral blood showed bright kappa surface immunoglobulin (Ig) light chain restricted B cells that were dim CD20 positive, partially CD5 positive, CD23 positive, bright CD79b positive, FMC7 negative, and CD10 negative (Table 2). The bone marrow showed similar immunophenotypic findings as the peripheral blood although all the monoclonal B-cells were CD5 negative, and both CD20 and the surface immunoglobulin staining intensity were bright. Conventional cytogenetic studies showed a complex karyotype with both numerical and structural anomalies detailed in Table 3. Fluorescence in situ hybridization (FISH) studies demonstrated cyclin D1 (CCND1) and Ig heavy chain fusion in $93.8 \%$ of the 500 nuclei examined compatible with $t(11 ; 14)$ (q13;q32); this abnormality was not identified by the conventional cytogenetics. Based on the results of all of the above studies, MCL was diagnosed. 
TABLE 1. Clinical Findings at Presentation

\begin{tabular}{|c|c|c|c|c|c|c|c|}
\hline $\begin{array}{l}\text { Case } \\
\text { No. }\end{array}$ & Age (y)/sex & $\begin{array}{c}\text { Absolute } \\
\text { Lymphocyte } \\
\text { Count (per } \mu \mathrm{L} \text { ) }\end{array}$ & Adenopathy & Splenomegaly & $\begin{array}{l}\text { Follow-up } \\
\text { (mo) }\end{array}$ & Initial Dx & Final Dx \\
\hline 1 & $71 / \mathrm{F}$ & 134,796 & Present & Present & $\mathrm{D}(49)$ & CLL/PL & MCL \\
\hline 2 & $54 / \mathrm{F}$ & 66,309 & Present & Present & D (19) & CLL & MCL \\
\hline 3 & $78 / \mathrm{F}$ & 22,670 & Absent & Present & A (3) & CLL/PL & MCL \\
\hline 4 & $71 / \mathrm{M}$ & 11,765 & Present & Unknown & $\mathrm{A}(60)$ & CLL & MCL \\
\hline 5 & $89 / \mathrm{M}$ & 56,588 & Absent & Absent & $\mathrm{D}(50)$ & CLL & FL \\
\hline 6 & $57 / \mathrm{M}$ & 24,624 & Present & Present & A (6) & PLL & FL \\
\hline
\end{tabular}

A, alive; D, dead.

TABLE 2. Flow Cytometric Immunophenotypic Findings

\begin{tabular}{|c|c|c|c|c|c|c|c|c|}
\hline $\begin{array}{l}\text { Case } \\
\text { No. }\end{array}$ & Specimen & CD5 & CD10 & CD23 & FMC7 & CD79b & $\begin{array}{c}\text { CD20 } \\
\text { Intensity }\end{array}$ & $\begin{array}{l}\text { Light Chain } \\
\text { (Intensity) }\end{array}$ \\
\hline \multirow[t]{2}{*}{1} & PB & + & - & + & - & + & Dim & Kappa (bright) \\
\hline & $\mathrm{BM}$ & - & - & + & - & + & Bright & Kappa (bright) \\
\hline 2 & $\mathrm{~PB}$ & + & - & - & + & + & Bright & Kappa (bright) \\
\hline 3 & $\mathrm{BM}$ & + & - & + & + & + & Bright & Kappa (bright) \\
\hline 4 & $\mathrm{~PB}$ & + & ND & $+/ \operatorname{dim}$ & ND & ND & Dim & Lambda (bright) \\
\hline 5 & PB & + & ND & ND & ND & ND & NA & Lambda (NA) \\
\hline 6 & $\mathrm{~PB}$ & - & $+/ \operatorname{dim}$ & - & ND & ND & Bright & Lambda (bright) \\
\hline
\end{tabular}

PB, peripheral blood; BM, bone marrow; ND, not done; NA, not available; +, positive; -, negative.

TABLE 3. Cytogenetic Findings

\begin{tabular}{|c|c|}
\hline $\begin{array}{l}\text { Case } \\
\text { No. }\end{array}$ & Cytogenetic Results \\
\hline 1 & $\begin{array}{l}\text { 45, XX, } \operatorname{add}(2)(\mathrm{q} 27), \operatorname{add}(3)(\mathrm{p} 11), \operatorname{add}(6)(\mathrm{p} 11.2), \operatorname{add}(9)(\mathrm{q} 34), \\
\operatorname{add}(10)(\mathrm{p} 11.2), \operatorname{add}(18)(\mathrm{q} 21),-22[12] . \\
\text { FISH: CCND1/IgH fusion in } 93.8 \% \text { of } 500 \text { nuclei. }\end{array}$ \\
\hline 24 & $\begin{array}{l}\text { 46, XX, } \operatorname{add}(5)(\mathrm{p} 15.1), \operatorname{del}(8)(\mathrm{p} 11.2), t(11 ; 14)(q 13 ; q q 32),[19] / 46, \\
\text { idem, } \operatorname{add}(12)(\mathrm{p} 13)[1] / 47, \mathrm{X}, \operatorname{add}(\mathrm{X}),(\mathrm{p} 22.1), \operatorname{add}(5)(\mathrm{p} 15.1),-8, \\
\mathrm{t}(11 ; 14)(\mathrm{q} 13 ; \mathrm{q} 32),+17,+\operatorname{mar}[1] .\end{array}$ \\
\hline 34 & $\begin{array}{l}42-43, \mathrm{X},-\mathrm{X}, \mathrm{t}(1 ; 16)(\mathrm{p} 13 ; \mathrm{q} 22),-3, \operatorname{del}(6)(\mathrm{q} 21), \operatorname{del}(7)(\mathrm{q} 11.2),-8, \\
\operatorname{der}(9), \mathrm{t}(9: 11)(\mathrm{q} 34 ; \mathrm{q} 13),-10, \operatorname{del}(11)(\mathrm{q} 11.2), \operatorname{der}(12) \mathrm{t}(7 ; 12) \\
(11.2 ; \mathrm{p} 11.20,-13, \operatorname{add}(13)(\mathrm{q} 32), \operatorname{der}(17 ; 18)(\mathrm{q} 10 ; \mathrm{q} 10), \operatorname{add}(18) \\
(\mathrm{q} 23), \operatorname{add}(19)(\mathrm{p} 13.3),-22,+\operatorname{der}(?) \mathrm{t}(3 ; ?)(\mathrm{p} 21 ; ?),+2 \mathrm{mar}[\mathrm{cp} 6] / 44, \\
\mathrm{XX}, t(11 ; 14)(q 13 ; q 32),-13,-16[1] / 46, \mathrm{XX}[13] \\
\text { FISH: CCND1/IgH fusion in } 46 \% \text { of } 500 \text { nuclei. }\end{array}$ \\
\hline 4 & $\begin{array}{l}\text { 46, XY, } t(11 ; 14)(q 13 ; q 32)[30], \text { NCA } 47, \text { idem }+14[1], 47, \text { idem } \\
+ \text { mar[1], } 46, \mathrm{XY}[9] .\end{array}$ \\
\hline $5 t$ & $t(14 ; 18)(q 32 ; q 21) \mathrm{t}(6 ; 19)(\mathrm{q} 12 ; \mathrm{q} 12)$ \\
\hline 6 & $\begin{array}{l}46, \mathrm{XY} \text {. } \\
\text { FISH: IgH/BCL2 fusion in } 87.4 \% \text { of } 500 \text { nuclei. }\end{array}$ \\
\hline
\end{tabular}

Initially the patient received Fludarabine based on the history of CLL but was subsequently changed to Cyclophosphamide, Adriamycin, and Teniposide (multimodality, mantle cell protocol therapy). Although there was an initial response to therapy, the patient died in October 2001, 4 years after initial presentation.

\section{Case 2}

A 54-year-old female with a history of adult-onset diabetes presented with complaints of night sweats, pruritus, fatigue, and dry mouth in August of 1998. Complete blood cell count showed absolute lymphocytosis (white blood cell count of $71.3 \times 10^{9} / \mathrm{L}$; lymphocytes 93\%). A presumptive diagnosis of CLL was made, and no further workup was done. In December of the same year, repeat evaluation showed white blood cell count of $180 \times 10^{9} / \mathrm{L} ; \mathrm{Hgb}$, $9.8 \mathrm{~g} / \mathrm{dL}$; Hct, $30.5 \%$; and PLT, $42 \times 10^{9} / \mathrm{L}$. The differential showed $91 \%$ lymphocytes and $9 \%$ neutrophils. Most lymphocytes (Fig. 2A) were small with condensed chromatin and scant cytoplasm; there were also rare cells compatible with prolymphocytes. A bone marrow specimen showed an extensive diffuse, lymphoid infiltrate (Fig. 2B) comprised of small, mature-appearing cells. The morphologic impression was CLL. Immunophenotyping by flow cytometry of the peripheral blood showed that the cells were CD5 positive, kappa surface Ig light chain restricted B cells with bright surface Ig and CD20 staining intensity, CD23 negative, bright $\mathrm{CD} 79 \mathrm{~b}$ positive, FMC7 positive, and CD10 negative (Table 2). Computed tomography (CT) scan demonstrated massive hepatosplenomegaly and enlarged lymph nodes in the axillae and abdomen. Because the flow cytometry results were not typical for CLL, an axillary lymph node biopsy was done; the lymph node showed effaced architecture by a mostly diffuse and vaguely nodular proliferation of small lymphocytes (Fig. 2C). There were no proliferation centers. Cyclin-D1 immunostain performed on the lymph node was positive (Fig. 2D). Conventional cytogenetic studies of the bone marrow demonstrated a complex female karyotype with $\mathrm{t}(11 ; 14)$ (q13;q32) in three metaphases (Table 3). MCL in leukemic phase was diagnosed based on the combination of morphologic, immunophenotypic, immunohistochemical, and cytogenetic findings.

The patient received chemotherapy as well as radiation to the spleen. One year after initial diagnosis (August 1999), hepatosplenomegaly and 

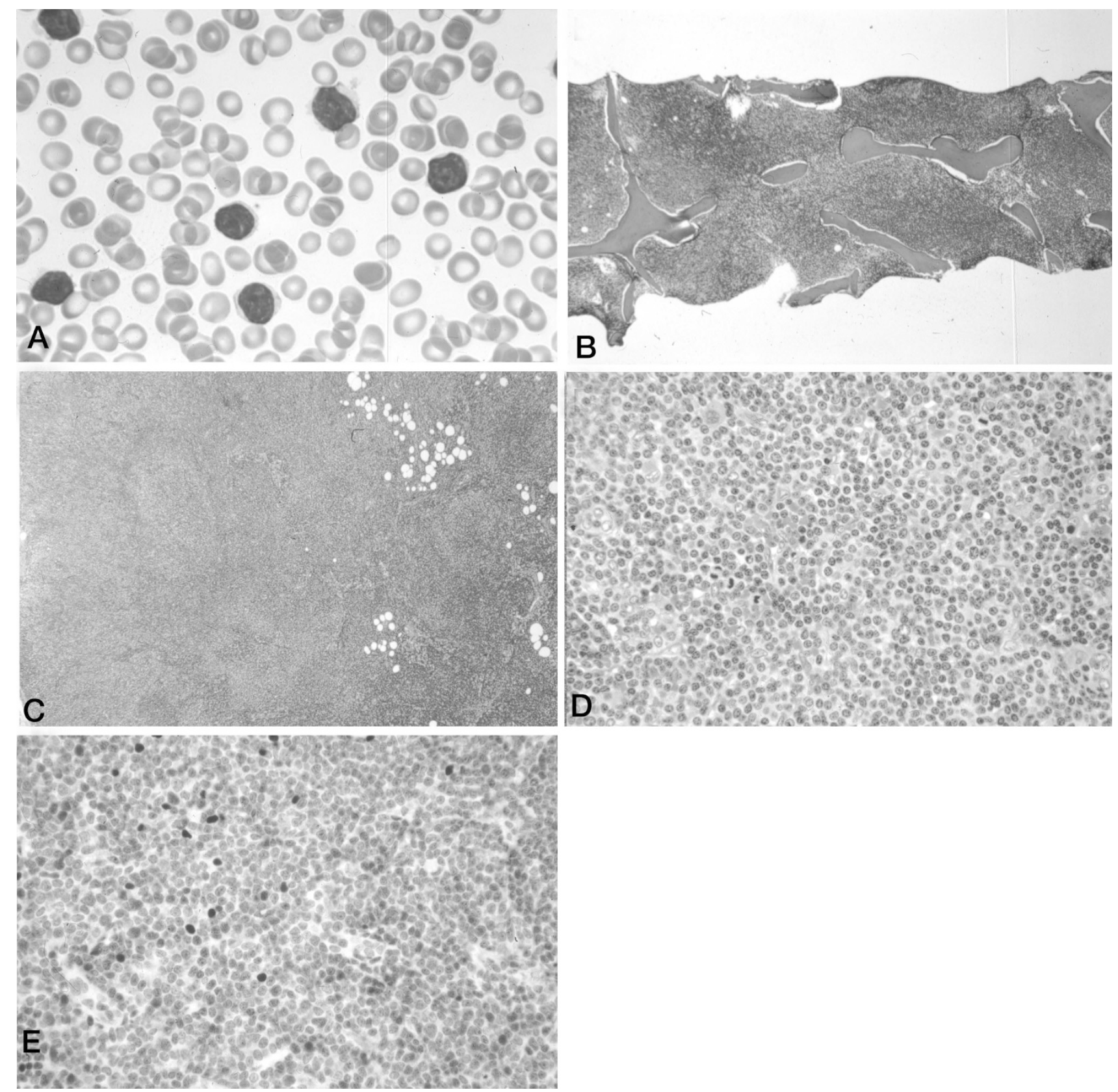

B

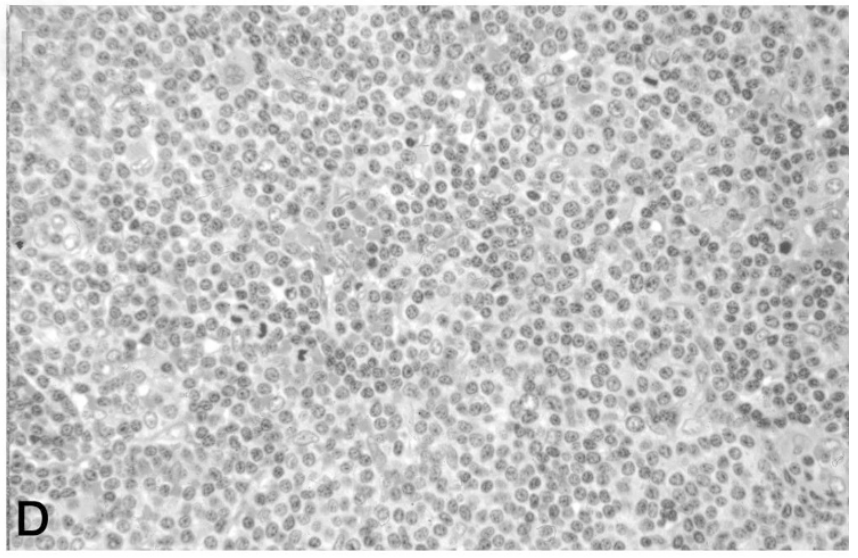

FIGURE 2. Patient 2. A, Peripheral blood smear with mantle cell lymphoma. The circulating lymphocytes are small with clumped chromatin, very similar appearing to those in chronic lymphocytic leukemia. B, Bone marrow core biopsy. This mantle cell lymphoma completely replaces the normal hematopoietic elements with an extensive diffuse infiltrate. C-E, Lymph node biopsy from patient 2 shows replacement by mantle cell lymphoma with a vaguely nodular growth pattern. Note the absence of proliferation centers. D, Higher magnification of Panel $\mathbf{C}$. The lymphoma cells are small and mature appearing. Several mitoses are present within the infiltrate. E, Cyclin-D1 immunostain of the lymph node biopsy. Note the characteristic variable intensity of the positive nuclei.

lymphadenopathy had resolved. She completed chemotherapy 2 months later, but disease recurred, and she died in March 2000.

\section{Case 3}

A 78-year-old female complained of fatigue and early satiety in September 2001. Physical examination showed marked splenomegaly and no lymph- adenopathy. Complete blood cell count showed white blood cell count of $21.8 \times 10^{9} / \mathrm{L} ; \mathrm{Hgb}, 10.5$ g/dL; Hct, $33.2 \%$; and PLT, $177 \times 10^{9} / \mathrm{L}$. The white blood cell count differential showed $87 \%$ lymphocytes, $10 \%$ neutrophils, $1 \%$ monocytes, and $2 \%$ basophils. The lymphocytes were mostly small and mature appearing, but 25\% were large with loosely condensed chromatin and distinct nucleoli (Fig. 3). 


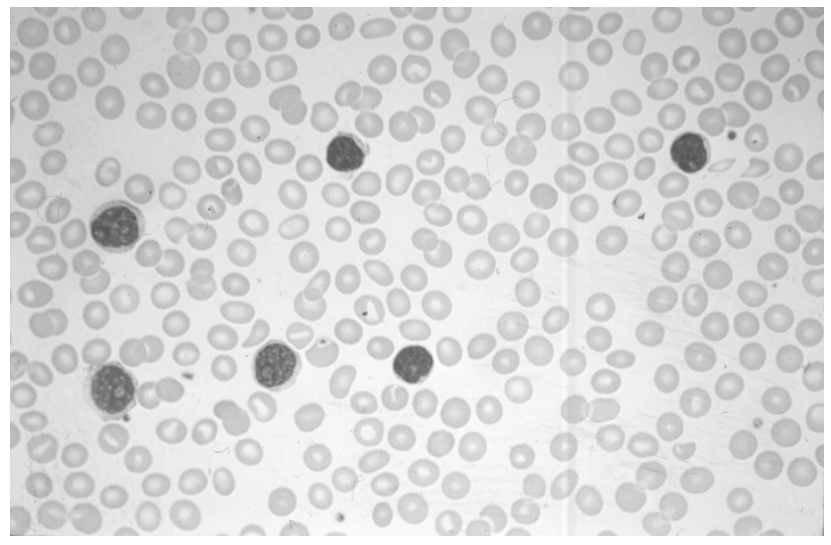

FIGURE 3. Peripheral blood (Patient 3) showing circulating mantle cell lymphoma. Most of the lymphocytes are small and mature appearing; rare lymphocytes have visible nucleolus.

A bone marrow core biopsy showed an interstitial lymphoid infiltrate with a focally nodular and intrasinusoidal component composed of small cells with condensed chromatin. Immunophenotyping of the bone marrow by flow cytometry showed that the cells were CD5 positive, bright kappa surface immunoglobulin light chain restricted $\mathrm{B}$ cells that were bright CD20 positive, CD23 positive, CD79b positive, and FMC7 positive. CLL/PLL was thought to be the most likely diagnosis, but cytogenetic studies were suggested because the immunophenotypic and the morphologic findings were not typical.

Conventional chromosomal banding of the bone marrow showed an abnormal female karyotype with multiple structural and numeric abnormalities (Table 3$)$, including one cell with $t(11 ; 14)$ (q13;q32). Interphase FISH studies with locus-specific probes for 11q23 (CCND1) and 14q32 (IgH) showed that $46 \%$ of 500 nuclei had fusion of CCND1 and IgH. Mantle cell lymphoma was diagnosed, and antiCD20 (Rituximab) therapy was begun.

\section{Case 4}

In December 1991, a routine complete blood cell count performed on a 69-year-old man showed white blood cell count of $18.1 \times 10^{9} / \mathrm{L} ; \mathrm{Hgb}, 16.4$ g/dL; Hct, $47.5 \%$; and PLT, $203 \times 10^{9} / \mathrm{L}$. The differential showed $64.8 \%$ lymphocytes, $29.8 \%$ neutrophils, $4.6 \%$ monocytes, $0.7 \%$ eosinophils, and $0.1 \%$ basophils. The lymphocytes were mostly small, with scant cytoplasm and condensed chromatin (Fig. 4) An occasional lymphocyte was larger, with more ample cytoplasm and visible nucleolus. Reevaluation 2 years later in March 1993 showed similar complete blood cell count and differential findings and absence of lymphadenopathy based on physical examination. Flow cytometric studies performed on the peripheral blood showed a predom-

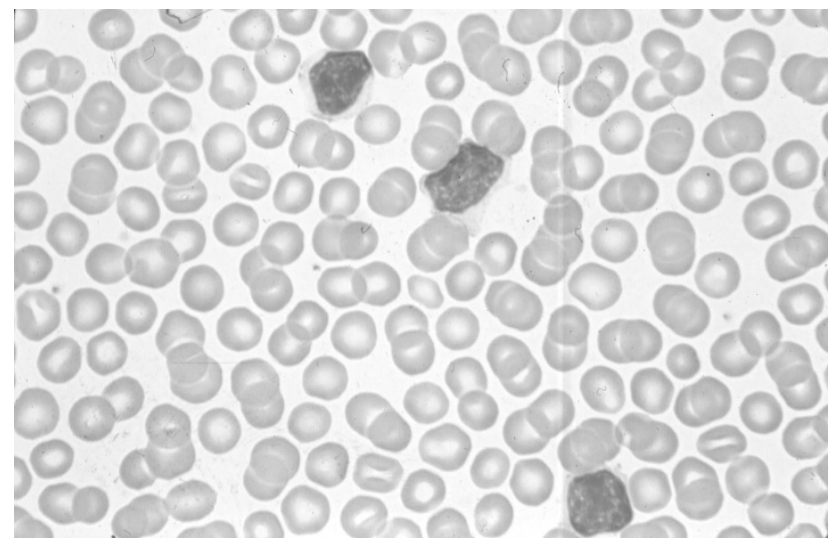

FIGURE 4. Peripheral blood (Patient 4) with mantle cell lymphoma. The lymphocytes are small and mature appearing.

inant population of CD5-positive, bright lambda surface Ig light chain restricted B cells that were dimly positive for CD20, CD22, and CD23 (Table 2). The morphologic and immunophenotypic findings were interpreted as consistent with CLL, and he was not treated. However, conventional cytogenetic studies of the peripheral blood showed an abnormal mosaic male karyotype with $\mathrm{t}(11 ; 14)(\mathrm{q} 13 ; \mathrm{q} 32)$ (Table 3). The case was reclassified as MCL based on the cytogenetic findings.

At last follow-up in November 1996, the patient had developed lymphadenopathy in the left axilla and the white blood cell count had increased to $31.7 \times 10^{9} / \mathrm{L}$ with $80 \%$ lymphocytes; the remainder of the complete blood cell count was essentially unchanged from the values obtained in 1991. Radiologic studies were planned to evaluate the extent of the lymphadenopathy before initiating chemotherapy when he was lost to follow-up.

\section{Case 5}

An 89-year-old man with history of CLL diagnosed in May 1986 was hospitalized on multiple occasions for treatment of urosepsis and pneumonia. Physical examination showed no lymphadenopathy or other organomegaly. Complete blood cell count performed in 1989 showed white blood cell count of $65.8 \times 10^{9} / \mathrm{L} ; \mathrm{Hgb}, 12.5 \mathrm{~g} / \mathrm{dL}$; and PLT, $212 \times 10^{9} /$ L. The peripheral blood (Fig. 5A) showed a uniform population of small lymphocytes with condensed chromatin and scant cytoplasm. Only rare lymphocytes showed slight nuclear indentations. Flow-cytometric studies of the peripheral blood showed CD19-positive, CD5-positive, lambda surface Ig light chain restricted B cells. The staining intensity of surface Ig was not available and CD10 or CD23 were not studied, but the phenotype was interpreted as being consistent with CLL. A bone marrow biopsy (Fig. 5B) showed a nodular, non-paratrabecular lymphoid infiltrate 


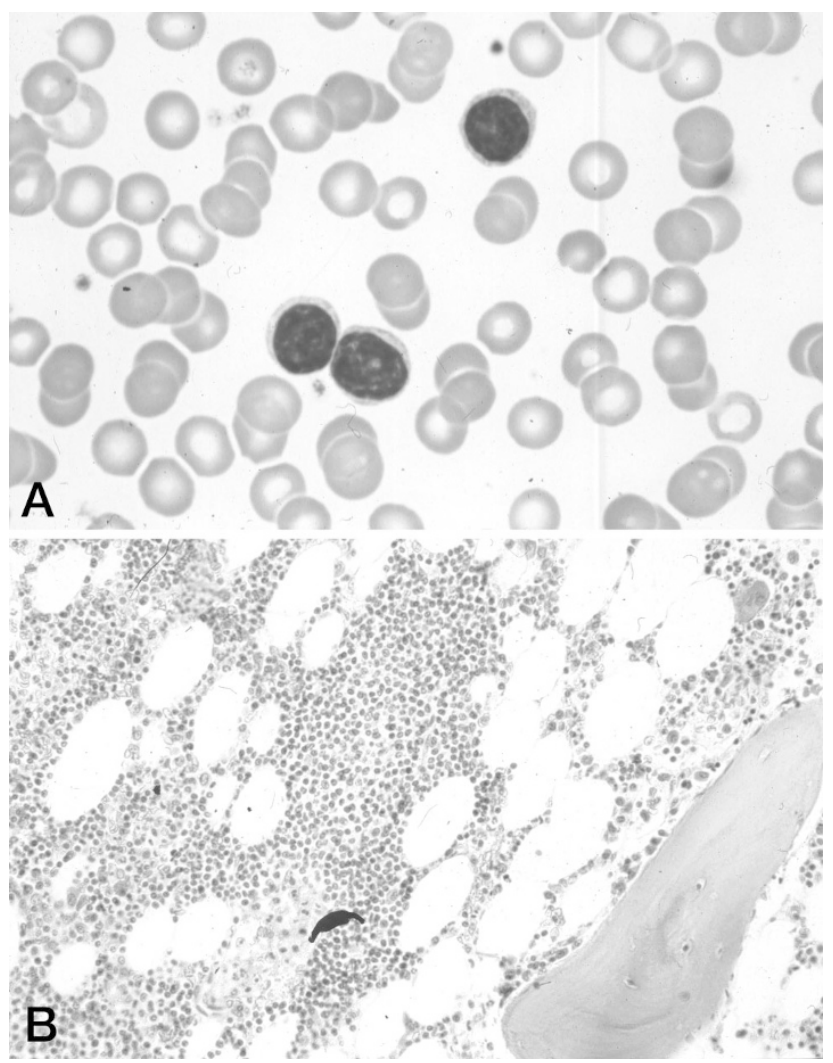

FIGURE 5. A, Peripheral blood (Patient 5) with follicular lymphoma showing lymphocytes that have round nuclei and clumped chromatin. B, Bone marrow core biopsy. Note the lymphoid aggregate adjacent to but not touching the bony trabeculum.

composed of small, mature appearing cells. There were also focal areas with an interstitial infiltrate.

Conventional cytogenetic studies performed on the peripheral blood showed an abnormal male karyotype with $\mathrm{t}(14 ; 18)(\mathrm{q} 32 ; \mathrm{q} 21)$. Repeat studies on three other occasions, once in 1989 and twice in 1999 , showed the $t(14 ; 18)$ in addition to $t(6 ; 19)$ (p12; q12) (Table 3).

Based primarily on the complete blood cell count and the morphologic findings in the peripheral blood, CLL was diagnosed initially. However, the case was subsequently reclassified as follicle center cell lymphoma with leukemic phase after correlation with the cytogenetic results. The patient was not treated for lymphoma and died in September 1990, almost 4 years after the initial diagnosis.

\section{Case 6}

A 57-year-old man presented in June 2000 with complaints of repeated episodes of lightheadedness, weakness, and dark stools. Physical examination showed mild splenomegaly without peripheral lymphadenopathy. However, CT scan of the chest and abdomen subsequently demonstrated enlarged lymph nodes in the mesentery, retroperitoneum, and celiac region. Complete blood cell count showed white blood cell count of $30.4 \times 10^{9} / \mathrm{L}$; Hgb, $11.3 \mathrm{~g} / \mathrm{dL}$; HCT, 33\%; and PLT, $175 \times 10^{9} / \mathrm{L}$. The differential showed $81 \%$ lymphocytes. The lymphocytes (Fig. 6A) were predominantly medium to large, with moderate amount of pale blue cytoplasm, round central nuclei, coarse chromatin, and a single central nucleolus. Occasional small lymphocytes with condensed chromatin and notched nuclei were also present. Imunophenotyping by flow cytometry of the peripheral blood showed CD5-negative, CD23-negative, partially CD10 positive (dim), bright lambda surface Ig light chain restricted B-cells. A bone marrow specimen (Fig. 6B) demonstrated extensive interstitial and diffuse infiltrate of large lymphoid cells. Prolymphocytic leukemia was thought to be the most likely diagnosis based on the morphology, and physical findings. Because of the CD10 positivity, cytogenetic studies were performed.

Conventional cytogenetic studies performed on the peripheral blood showed a normal 46, XY (20) karyotype. However, interphase FISH studies using locus-specific probes for $14 \mathrm{q} 32$ (IgH) and 18q21.3 (BCL2) were performed. The results showed that

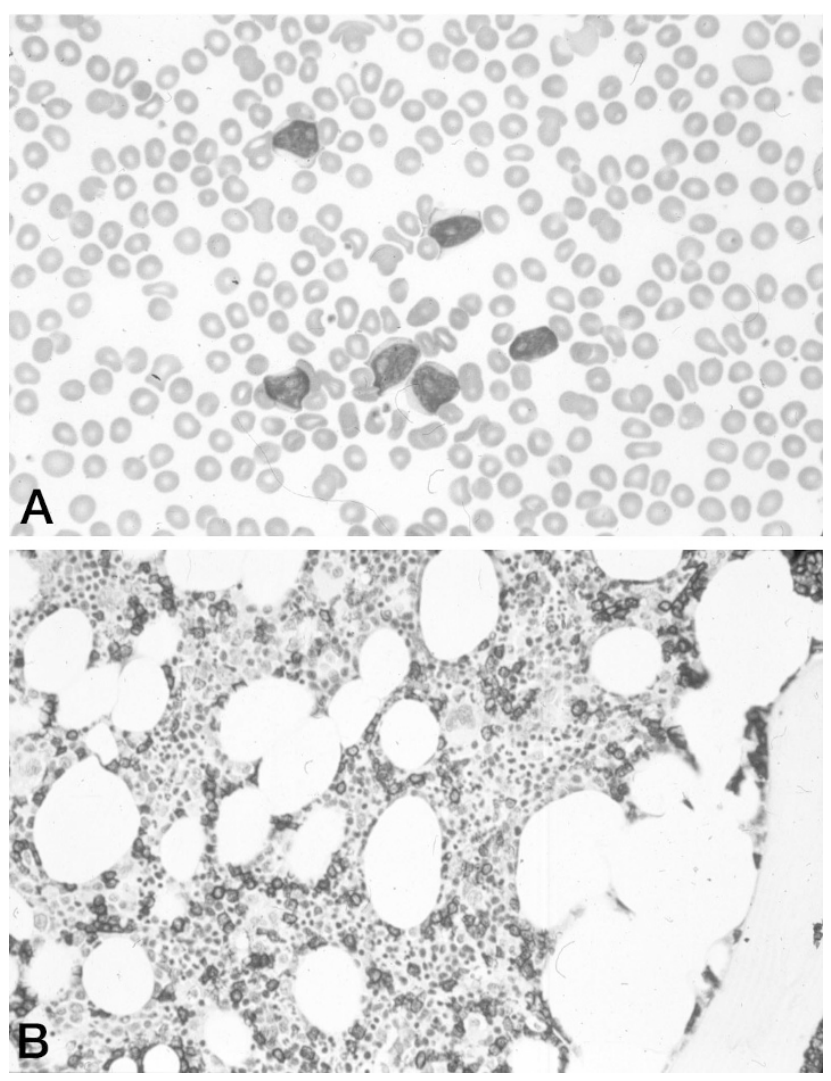

FIGURE 6. Patient 6. A, Peripheral blood with follicular lymphoma. The circulating lymphoma cells are medium sized with ample cytoplasm, clumped chromatin and distinct nucleolus, thus resembling prolymphocytes. B, CD20 immunostain of the bone marrow core biopsy shows a focus with an interstitial infiltrate. Elsewhere, the infiltrate was diffuse. 
$87.4 \%$ of 500 nuclei had BCL2/IgH fusion compatible with $\mathrm{t}(14 ; 18)$. Although PLL was considered initially, a large cell, follicle center cell lymphoma in leukemic phase was diagnosed based on the cytogenetic findings.

The patient was treated with Cyclophosphamide, Adriamycin, Prednisone, and Vincristine (CHOP) chemotherapy and reevaluated in August 2000 because the white blood cell count remained abnormal at $24.6 \times 10^{9} / \mathrm{L}$. Physical examination at reevaluation did not show lymphadenopathy, but there was mild splenomegaly. He received additional CHOP chemotherapy including intrathecal administration and received cranial radiation because of meningeal involvement by the lymphoma. At last follow-up, in December 2000, he was alive with residual disease.

\section{DISCUSSION}

Six cases of B-cell non-Hodgkin's lymphomas that presented with a prominent peripheral blood absolute lymphocytosis and that exhibited blood and bone marrow morphology indistinguishable from CLL, CLL/PLL, or PLL are reported. Four cases initially considered to be CLL or CLL/PLL were positive for $\mathrm{t}(11 ; 14)$ (q13;q32) and were subsequently diagnosed as MCL with a leukemic presentation; two cases initially considered to be CLL or PLL were $\mathrm{t}(14 ; 18)$ (q32;q21) positive and were classified as FCLs with a leukemic presentation.

Immunophenotyping by flow cytometry was performed on the four cases of MCL; only one showed a phenotype typical for MCL. This CD23-negative case was unusual for CLL and prompted a lymph node biopsy as well as the cytogenetic studies that confirmed the diagnosis of MCL. In the other three cases of MCL, the phenotype was not definitive for either MCL or CLL. As is typical of both neoplasms, all three cases were CD5 positive. CD23 was positive in all three cases supporting CLL. The CD23 positivity was dim in one of the three cases, but this is not discriminating because both MCL and CLL may be dim CD23 positive (12). Even though all three patients had bright surface Ig light chain intensity and two had bright CD20 staining, these findings were insufficient for a definitive diagnosis. Bright-surface Ig light chain and bright CD20 staining intensity are more often observed in MCL and FCL than in CLL (13), but considerable overlap occurs. In one large series of 93 patients with CLL, $26 \%$ had strong CD20 expression, whereas $24 \%$ had strong surface Ig light-chain expression (14). FMC7 has been proposed to be one of the most reliable markers to help differentiate other B-cell neoplasms from CLL which is typically FMC7 negative $(15,16)$. Our experience also supports this view (17).
However, only one of the above three cases was FMC7 positive; thus, although FMC7 may point to a non-CLL lymphoid neoplasm, it was not a reliable marker to rule out CLL in these cases. Bright CD79b staining was also present in all three MCL studied. CD79b positivity is unusual for CLL. In one study, only $5 \%$ of 330 CLL cases were CD79b positive (18); and when cases with "atypical morphology" were excluded, only $2.3 \%$ of CLL were positive. MCL and FCL were CD79b positive in slightly $>90 \%$ and $80 \%$ of cases, respectively, in this same series (18). Although not specific, bright CD79b positivity may be an important clue to further evaluate cases that on initial impression are thought to be CLL.

Three of the patients with MCL had bone marrow biopsies; the morphology of the lymphoma did not distinguish between CLL and MCL. The lymphoid infiltrates in the trephine biopsies were interstitial, diffuse, or focal random, patterns that also occur in CLL. Paratrabecular infiltrates, a feature that would be strongly against the diagnosis of CLL, were not identified. Proliferation centers were not identified but are not present in the bone marrow in the majority of cases of CLL. Cyclin-D1 (BCL-1) immunostain is valuable to confirm a diagnosis of MCL. However, B5-fixed bone marrow trephine biopsies and clot sections involved by MCL are consistently cyclin-D1 negative in our laboratory. False-negative cyclin-D1 stain has also been reported in B5-fixed tissues by others (19). Although cyclin-D1 immunostain has been used successfully in B5-fixed bone marrow specimens $(20,21)$, staining intensity is reported to be weaker in the B5-fixed bone marrow specimens (20). Cyclin-D1 stain was positive in the single case (Case 2) in this report in which formalinfixed lymph node tissue was available.

When the diagnosis of CLL in the blood or bone marrow is not clear, a lymph node biopsy will usually clarify the diagnosis. One patient (Patient 2) had a lymph node biopsy because the immunophenotype obtained from the peripheral blood was unusual for CLL. However, the remaining patients did not have lymph node biopsies because they were felt to have CLL and lymph node biopsies are not routinely performed at diagnosis in CLL, because there was no lymphadenopathy, or because enlarged lymph nodes were not easily accessible.

Although peripheral blood involvement occurs in $\leq 77 \%$ of MCL (22), the number of circulating lymphoma cells is typically low; most cases do not present with absolute lymphocytosis even when there are circulating lymphoma cells $(4,9)$. In addition, the morphology of the circulating lymphoma cells usually differs from CLL because the nuclei of the lymphoma cells are often irregular, with frequent visible nucleoli. However, cases with features that mimic CLL have been described $(7,23$, 24). Bosch et al. (23), in their series of 59 MCLS, 
noted that some were initially misclassified as atypical CLL, although the extent of blood involvement and detailed morphologic and phenotypic information were not provided. Wong et al. (7) described 14 patients with MCL in leukemic phase that resembled chronic lymphoproliferative disorders. Four patients in the Wong's series had lymphocytosis at diagnosis composed of small, mature appearing cells with occasional admixed prolymphocyte-like cells similar to the cases we present. Schlette et al. (24) described leukemic MCL in 23 patients who all had absolute lymphocytosis at initial diagnosis. Seventy percent $(16 / 23)$ of the patients in the Schlette et al. series were referred with a diagnosis of CLL. Although some of these patients had circulating lymphoma cells that resembled CLL, the number of cases or detailed phenotype were not provided for this group of patients. However, misdiagnosis of MCL as CLL seems to be a common occurrence.

One of the six cases initially interpreted as CLL in this series was classified as FCL with leukemic presentation after conventional chromosomal banding revealed $t(14 ; 18)$ (q32; 21$)$. Only limited immunophenotypic data was available for this patient, and information regarding CD10, CD23, and surface Ig intensity was not available. CD5 was positive; this is unusual for FCL but has been previously reported (25). A bone marrow biopsy showed several focal, non-paratrabecular lymphoid infiltrates; a pattern often observed in CLL. Others have classified similar cases with 14q32 abnormality as CLL (26), but we choose to separate this case from CLL because the IgH/BCL2 fusion product is typical for FCL (27, 28).

An additional $\mathrm{t}(14 ; 18)$ (q32;q21)-positive case (Case 6) was initially considered to be PLL based on morphology. The clonal B cells were CD5 and CD23 negative, similar to the phenotype of PLL $(1,29)$; however CD10 was dimly positive, and this was unusual for PLL. Therefore FISH studies using probes for $\mathrm{t}(14 ; 18)$ were performed to evaluate for FCL. IgH/BCL2 fusion compatible with $t(14 ; 18)$ (q32;q21) was detected, and this case was classified as a large cell lymphoma of follicle center cell origin. A follicular growth pattern could not be excluded based solely on the morphologic findings in the peripheral blood and bone marrow, and no other tissues were available for evaluation. The $t(14$; 18) with BCL-2 gene rearrangement has been detected in 20 to $28 \%$ of diffuse large B-cell lymphomas (DLBCL) $(28,30)$. It is worth noting that a recent study showed that DLBCL without follicular growth pattern and with $t(14 ; 18)$ have gene expression profile resembling normal germinal-center B cells (28). This finding would support classification of lymphomas with $t(14 ; 18)$ as being of follicle center cell origin.
Patients with FCL may present with absolute lymphocytosis in $\leq 23 \%$ of cases (31). The circulating lymphoma cells are typically small with scant cytoplasm and cleaved nuclei $(25,31)$. Both long-term survival (31) and poor response to chemotherapy (25) have been observed in these patients. Leukemic follicle center cell lymphoma resembling PLL has not been reported previously, to our knowledge.

Of note, Schlette et al. (8) recently reported leukemic MCL that also resembled PLL. In their series of 20 PLL, $t(11 ; 14)$ was demonstrated in four cases that were ultimately classified as MCL. In light of the findings by Schlette et al. (8) and Case 6 in this series, PLL should be considered only after excluding non-Hodgkin lymphomas such as mantle cell and FCL. In fact, PLL may need to be reevaluated as a distinct entity.

The presence or absence of organomegaly did not help to distinguish these non-Hodgkin lymphomas from CLL because although patients with lowstage CLL often do not present with organomegaly, those with advanced-stage disease commonly do. Because most patients with MCL and FCL present with lymphadenopathy $(4,9,32)$, the absence of organomegaly in one patient with FCL and the absence of lymphadenopathy in one with MCL were unusual and may further contribute to confusion with CLL. The patient with IgH/BCL2 fusion (Case 5) who lacked organomegaly was evaluated only by physical examination; CT scans or other radiologic studies were not performed to evaluate for intraabdominal lymphadenopathy. Lymphadenopathy was detected only with CT scans in the other patient with IgH/BCL2 fusion (Case 6); it is possible that similar studies could have revealed lymphadenopathy in Case 5. Although unusual, cases of MCL that lack lymphadenopathy at diagnosis (22) and cases that present with prominent splenomegaly, absence of lymphadenopathy, and leukemic phase have been reported (33). Similar to our cases of MCL, the series of 8 patients reported by Molina $e t$ al. (33) all had $\mathrm{t}(11 ; 14)$ (q13;q32), but unlike our cases, most (6/8) had phenotype consistent with MCL. The authors were able to demonstrate strong expression of cyclin-D1 protein in extracts obtained from the peripheral blood mononuclear cells using western blot analysis although cyclin-D1 immunostain could not be performed on the bone marrow specimens processed in Bouin's fixative.

Although there are difficulties in separating CLL from some non-Hodgkin lymphoma, distinction is important because prognostic and therapeutic differences exist. Despite treatment with combination chemotherapy for aggressive lymphoma, median overall survival for MCL ranges from 3-5 years (9, 31), whereas CLL has a median survival of 10 years (2), and indolent FCL has median survival of 8 to 10 years (34). In addition, many patients with low- 
stage CLL receive no therapy until there is progression of disease $(1,2)$.

The initial impression of CLL is usually ascertained from a peripheral blood lymphocytosis composed of small, mature-appearing cells. Immunophenotyping has become an essential tool to confirm the diagnosis and to separate CLL from other lymphoid malignancies. Bone marrow trephine biopsies are also helpful because the presence of paratrabecular aggregates exclude the diagnosis of CLL. Although lymph node biopsies are not routinely performed at diagnosis of CLL, findings in a lymph node are often diagnostic; therefore, lymph node biopsies should be considered at initial diagnosis for cases of suspected CLL in which the findings are not typical. A positive cyclin-D1 immunostain excludes CLL and confirms the diagnosis of MCL. CLL cases are not routinely tested for cytogenetic abnormalities because there is no single pathognomonic karyotype (26). However, CLL cases may benefit from cytogenetic studies to provide prognostic information. Our report emphasizes that cytogenetic studies may also be important to exclude other non-Hodgkin lymphomas, especially when the morphology and/or immunophenotypic findings are not typical for CLL. Molecular cytogenetic studies to evaluate for specific translocations such as $t(11 ; 14)$ or $t(14 ; 18)$ should be considered if conventional chromosome banding does not reveal a clonal abnormality. Of note, one patient in our series (Case 1) had CCND1/IgH fusion demonstrated in $>90 \%$ of cells analyzed with FISH, whereas conventional chromosome banding did not detect this abnormality. In fact, molecular cytogenetic studies have been reported to detect genomic aberrations up to twice as frequently as chromosome banding (26).

\section{REFERENCES}

1. Chesson BD, Bennett JM, Grever M, Kay N, Keating MJ, O’Brien $\mathrm{S}$, et al. National cancer institute-sponsored working group guidelines for chronic lymphocytic leukemia: revised guidelines for diagnosis and treatment. Blood 1996;87:4990-7.

2. Mauro FR, Fao R, Giannarelli D, Cordone I, Crescenzi S, Pescarmona E, et al. Clinical characteristics and outcome of young chronic lymphocytic leukemia patients: a single institution study of 204 cases. Blood 1999;94:448-54.

3. Bennett JM, Catovsky D, Daniel M-T, Flandrin G, Galton DAG, Gralnick HR, et al. Proposals for the classification of chronic (mature) B and T lymphoid leukemias. J Clin Pathol 1989;42:567-84.

4. Criel A, Pittaluga S, Verhoef G, Wlodarska I, Meeus P, Mecucci C, et al. Small B-cell NHL and their leukemic counterpart: differences in subtyping and assessment of leukemic spread. Leukemia 1996;10:843-53.

5. Bernstein NL, Reis MD, Ngan BY, Sawka CA, Jamal HH, Kuzniar B. Detection of occult lymphoma in the peripheral blood and bone marrow of patients with untreated earlystage and advanced-stage follicular lymphoma. J Clin Oncol 1993;11:1344-52.
6. Lambrechts AC, Hupkes PE, Dorssers LC, van't Veer MB. Translocation (14;18)-positive cells are present in the circulation of the majority of patients with localized (stage 1 and 11) follicular non-Hodgkins lymphoma. Blood 1993;82:2510-6.

7. Wong K-F, Chang JKC, So JCC, Yu P-H. Mantle cell lymphoma in leukemic phase characterization of its broad cytologic spectrum with emphasis on the importance of distinction from other chronic lymphoproliferative disorders. Cancer 1999;86:850-7.

8. Schlette E, Bueso-Ramos C, Giles F, Glassman A, Hayes K, Medeiros J. Mature B-cell leukemias with more than 55\% prolymphocytes. A heterogeneous group that includes an unusual variant of mantle cell lymphoma. Am J Clin Pathol 2001;115:571-81.

9. Argatoff LH, Connors JM, Klasa RJ, Horsman DE, Gascoyne RD. Mantle cell lymphoma: a clinicopathologic study of 80 cases. Blood 1997;89:2067-79.

10. Peterson LC, Goolsby C. Flow cytometric immunophenotyping of hematological malignancies involving the blood and bone marrow. Curr Diagn Pathol 1997;4:187-95.

11. Peterson LC, Lindquist LL, Church S, Kay NE. Frequent clonal abnormalities of chromosome band 13q14 in B-cell chronic lymphocytic leukemia: multiple clones, subclones, and nonclonal alterations in 82 midwestern patients. Genes Chromosomes Cancer 1992;4:273-80.

12. Gong JZ, Lagoo AS, Peters D, Horvatinovich J, Benz P, Buckley PJ. Value of CD23 determination by flow cytometry in differentiating mantle cell lymphoma from chronic lymphocytic leukemia/small lymphocytic lymphoma. Am J Clin Pathol 2001;116:893-7.

13. Kilo MN, Dorfman DM. The utility of flow cytometric immunophenotypic analysis in the distinction of small lymphocytic leukemia from mantle cell lymphoma. Am J Clin Pathol 1996;105:451-7.

14. Tefferi A, Bartholmai BJ, Witzig TE, Li C-Y, Hanson CA, Phyliky RL. Heterogeneity and clinical relevance of the intensity of CD20 and immunoglobulin light-chain expression in B-cell chronic lymphocytic leukemia. Am J Clin Pathol 1996;106:457-61.

15. Matutes E, Owusu-Ankomah K, Morilla R, Marco JG, Houlihan A, Que TH, et al. The immunological profile of B-cell disorders and proposal of a scoring system for the diagnosis of CLL. Leukemia 1994;8:1640-5.

16. Huh YO, Pugh WC, Kantarjian MH, Stass SA, Cork A, Trujillo $\mathrm{JM}$, et al. Detection of subgroups of chronic B-cell leukemias by FMC7 monoclonal antibody. Am J Clin Pathol 1994;101: 283-9.

17. Kent SA, Peterson LC, James C, Marszalek L, Khoong A, Bachta DJ, et al. Pan B-cell markers are not redundant in analysis of chronic lymphocytic leukemia (CLL). In press.

18. Zomas AP, Matutes E, Morilla R, Owusu-Ankomah K, Seon BK, Catovsky D. Expression of the immunoglobulinassociated protein B29 in B cell disorders with the monoclonal antibody SN8 (CD79b). Leukemia 1996;10:1966-70.

19. Chen CC, Raikow RB, Sonmez-Alpan E, Swerdlow SH. Classification of small B-cell lymphoid neoplasms using a paraffin section immunohistochemical panel. Appl Immunohistochem Mol Morphol 2000;8:1-11.

20. Miranda RN, Briggs RC, Kinney MC, Veno PA, Hammer RD, Cousar JB. Immunohistochemical detection of cyclin D1 using optimized conditions is highly specific for mantle cell lymphoma and hairy cell leukemia. Mod Pathol 2000;13(12): 1308-14.

21. Vasef MA, Mederiros LJ, Koo C, McCourty A, Brynes RK. Cyclin D1 immunohistochemical staining is useful in distinguishing mantle cell lymphoma from other low-grade B-cell neoplasms in bone marrow. Am J Clin Pathol 1997;108: 302-7. 
22. Cohen PL, Kurtin PJ, Donovan KA, Hanson CA. Bone marrow and peripheral blood involvement in mantle cell lymphoma. Br J Haematol 1998;101:302-10.

23. Bosch F, Lopez-Guillermo A, Campo E, Ribera JM, Conde E, Piris MA, et al. Mantle cell lymphoma presenting features, response to therapy, and prognostic factors. Cancer 1998;82: 567-75.

24. Schlette E, Lai R, Onciu M, Dorota D, Bueso-Ramos C, Medeiros J. Leukemic mantle cell lymphoma: clinical and pathologic spectrum of twenty-three cases. Mod Pathol 2001;14:1133-40.

25. Melo JV, Robinson DSF, De Oliveria MP, Thompson IW, Lampert IA, Ng JP, et al. Morphology and immunology of circulating cells in leukemic phase of follicular lymphoma. J Clin Pathol 1988;41:951-9.

26. Dohner H, Stilgenbauer S, Benner A, Leupolt E, Krober A, Bullinger L, et al. Genomic aberrations and survival in chronic lymphocytic leukemia. N Engl J Med 2000; 343: 1910-6.

27. Horsman DE, Gascoyne RD, Coupland RW, Coldman AJ, Adomat SA. Comparison of cytogenetic analysis, southern analysis, and polymerase chain reaction for the detection of $\mathrm{t}(14 ; 18)$ in follicular lymphoma. Am J Clin Pathol 1995;103: 472-8.

28. Huang JZ, Sanger WG, Greiner TC, Staudt LM, Weisenburger DD, Pickering DL, et al. The $\mathrm{t}(14 ; 18)$ defines a unique subset of diffuse large B-cell lymphoma with a germinal center B-cell gene expression profile. Blood 2002;99:2285-90.

29. Hercher C, Robain M, Davi F, Garand R, Valensi F, Vandeputte $\mathrm{H}$, et al. The groupe francais d'hematologie cellulaire. A multicenter study of 41 cases of B-prolymphocytic leukemia: two evolutive forms. Leuk Lymphoma 2001;42:981-7.

30. Weiss LM, Warnke RA, Sklar J, Cleary ML. Molecular analysis of the $\mathrm{t}(14 ; 18)$ chromosomal translocation in malignant lymphomas. N Engl J Med 1987;317(19):1185-9.

31. Spiro S, Galton DAG, Wiltshaw E, Lohmann RC. Follicular lymphoma: a survey of 75 cases with special reference to the syndrome resembling chronic lymphocytic leukemia. $\mathrm{Br}$ J Cancer 1975;31 (Suppl II):60-72.

32. Swerdlow SH, Berger F, Isaacson PI, Muller-Hermelink HK, Nathwani BN, Piris MA, et al. Mantle cell lymphoma. In: Jaffe ES, Harria NL, Stein H, Vardiman JW, editors. World Health Organization classification of tumours. Pathology and genetics of tumours of haematopoietic and lymphoid tissues. Lyon, France: IARC Press, 2001. p. 168-70.

33. Molina TJ, Delmer A, Cymbalista F, Tourneau Al, Perrot J-Y, Ramond S, et al. Mantle cell lymphoma, in leukemic phase with prominent splenomegaly. A report of eight cases with similar clinical presentation and aggressive outcome. Virchows Arch 2000;437:591-8.

34. Horning SJ. Natural history of and therapy for the indolent nonHodgkin's lymphomas. Semin Oncol 1993;20 (Suppl 5):75-88. 